\title{
Managing Reverse Knowledge Flows in Routine Replication Programs: The Case of Global Manufacturing ERP Template Rollout
}

\author{
Marcin Kandora ${ }^{1}$
}

Submitted: 17.03.17. Final acceptance: 24.01.18

\section{Abstract}

Purpose: Acknowledging the key role of knowledge transfer as the primarily mechanism, through which firms replicate organizational routines, this paper addresses the role of reverse knowledge flows in routine replication programs and attempts identifying a set of mechanisms that could facilitate these knowledge flows. Furthermore, the article aims to provide a proposal for a structured approach to reverse knowledge flow management that would combine in the same framework (1) the deployment of routines in new contexts and (2) the collection, transformation, and redeployment of local knowledge.

Methodology: The applied methodology follows the interpretative research approach. It draws from a longitudinal study of a seven-year-long replication program, during which an ERP template has been deployed in twenty-five manufacturing sites and five regional offices of a leading multinational FMCG company. The main research method was participant observation complemented with interviews, project documentation, and e-mail communication analysis.

Findings: The paper shows that, in the course of multiple replications, the replicated template becomes subject to several adjustments in order to fit new requirements, eliminate observed shortcomings, and adopt learnings from previous deployment sites. The article further demonstrates that keeping such template enhancement process effective requires deliberate management of reverse knowledge flows, which maturity should grow in parallel to the scope of the program and number of replications. This means that reverse knowledge flows must increasingly base on well-established processes with assigned resources, clear responsibilities, and socio-material mechanisms. This is a prerequisite for the subsequent deployments and retrofits of an enriched template to become the key vehicle for the diffusion of local learnings on a company-wide scale.

Originality: This paper contributes to the literature on organizational routines by addressing the role of reverse knowledge flows in routine replication processes, proposing a structured approach to reverse knowledge flow management in routine replication programs, and presenting a maturity model for a reverse knowledge flow management system.

Keywords: routines; replication; knowledge; reverse knowledge flows

JEL: M10

1 Integration Manager at a multinational company; e-mail: mj.kandora@gmail.com 


\section{Introduction}

One of the most significant streams in contemporary research on organizational routines relates to their replication and transfer. The replication of a routine "involves the creation of another routine that is similar to the original routine in significant respect" (Szulanski and Jensen, 2004, p. 349) and scholars deem it successful when "broadly equivalent outcomes are realized by similar means" (Baden-Fuller and Winter, 2005, p. 8).

A rich body of literature addresses a variety of themes around replication, with considerable focus on the strategic dimension of replication (Szulanski and Winter, 2001), approaches to replication (template vs. principle; Baden-Fuller and Winter, 2005; Konlechner and Güttel, 2011), the nature of the replication process itself and its contingencies (Hodgson, 2009; Madhok, 1997; Winter and Szulanski, 2001; Szulanski and Winter, 2002; Konlechner, 2011), template design (Gupta, Hoopes and Knott, 2015), and how to find the right balance between the application of 'copying exactly' and 'local adaptation’ approaches (D’Adderio, 2014; Konlechner and Güttel, 2011).

The replication of organizational routines may occur, on the one hand, involuntarily and unconsciously through "spontaneous actions between organizational participants" (Patora-Wysocka, 2015, p. 9). Routines may also be replicated when employees move between departments or organizations and share their experiences, influencing the existing and newly designed routines (Hodgson, 2009; Aime et al., 2010). On the other hand, evidence shows that many routine replication attempts resemble a well-designed and systematically conducted process, especially in organizations which deliberately apply replication as primary means for achieving competitive advantage (Winter and Szulanski, 2001; Szulanski and Winter, 2002; Jonsson and Foss, 2011).

Extant literature shows that the following factors significantly influence the effects of routine replication: the degree of compliance with the template (Szulanski and Jensen, 2008; Rivkin, 2001), the 'goodness of fit' between the copied routine and host context (Madhok, 1997, p. 47), the level of replicatee's absorptive capacity (Maritan and Brush, 2003; Szulanski, 1996; Hodgson, 2009, p. 36), organizational culture (Bertels, Howard-Grenville and Pek, 2016), the relationship between the replicator and replicatee (Szulanski, 1996), the degree of knowledge codification (Konlechner, 2011), political frictions in the replication process (Friesl and Larty, 2013), environmental fit (Yan-Liang and Chuang, 2014), the quality of the template being replicated and its role in overcoming resistance to change (Szulanski and Jensen, 2004), regular enrichments of the template with local experiential knowledge through institutionalized 
mechanisms and structured processes (Jonsson and Foss, 2011) and the type of deviations from the template (Winter et al., 2012).

Undoubtedly, most of the above critical success factors relate to the knowledge transfer from the replicator to the replicatee (forward knowledge flows), effective transformation of this knowledge into knowing at the destination - i.e. achieving proficiency in routine execution as defined by W. Orlikowski, 2002 - and the inclusion of replicatee's feedback and lessons-learned into subsequent cycles of replication (reverse knowledge flows).

Acknowledging the key importance of knowledge transfer as the primarily means for accomplishing replication (Argote and Ingram 2000; Szulanski 1996; Baden-Fuller and Winter, 2005; Nelson and Winter, 1982; Becker and Lazaric, 2003; Zollo, Winter, 2002; Winter and Szulanski, 2002; Pisano, 1994; Szulanski, Cappetta and Jensen, 2004; Zander, Kogut, 1995), this paper addresses the role of the reverse knowledge flows in routine replication processes and aims to identify a set of mechanisms with which these can be facilitated. To do so, the article uses the findings from a longitudinal study of a seven-year-long replication program, during which an ERP template has been deployed within twenty-five manufacturing sites and five regional offices of a leading multinational FMCG company, where relevant research data has been collected by means of participant observation complemented with interviews, project documentation, and e-mail communication analysis.

M. Friesl and J. Larty (2013, p. 110-113) state that "empirical research on replication has only just started to unpack the role of these feedback loops in replication ... [and, in particular,] we know little about how changes, that may initially originate in local units, become legitimized and disseminated across the organization, thus influencing subsequent cycles of replication."

The paper consists of four major sections. First describes the replication process as such. Second considers the reverse knowledge flows and their role in replication processes. Third presents the case study findings and a set of mechanisms, which facilitate reverse knowledge flows in replication processes, from local units to the central functions, along with an explanation how these learnings may enrich the template's rollout. Fourth proposes a maturity model along with a structured approach for reverse knowledge flow management, followed by a summary. 


\section{The Nature of Routine Replication Processes}

Over the last twenty years, scholars have analyzed routine replication examples in both the literature and management practice. Moreover, in particular groups of companies like franchise chains, the ability to replicate constitutes the core of their business model and underpins their competitive advantage. At the same time, the evidence of failed replication attempts like the example of Rank Xerox (see Szulanski and Winter, 2002) still calls for research focus on the factors which determine the effectiveness of routine replication. The failed attempts also prove that the replication and transfer of routines is not a trivial task. The task is rather a complex undertaking, full of challenges, that requires a very good knowledge of the copied routines, advanced understanding of the target context, great intuition, and continuous observation whether the "transplanted" routine has been well accepted and if it has become fully operational within the new environment. Routine replication is particularly important during mergers and acquisitions, in operational excellence programs, and generally in the face of increasing globalization and dissemination of consumption patterns that stimulate companies to open their subsidiaries to novel markets.

Organizations that pursue replication strategies mainly aim at achieving tangible benefits. A successful replication may lead to economies of scale. The organizational studies literature points to three main value-creating mechanisms of replication strategies: (1) the strategy for growth (the McDonald's approach); (2) the means for improving overall efficiency (through the diffusion of "best practices" amongst organizational units); (3) the way for achieving high levels of flexibility (especially in dynamic markets or high-tech industries) (Friesl and Larty, 2013). Nevertheless, the key to gaining competitive advantage through replication essentially stems from the deployment of successful practices across sites, markets, or geographies faster than the competitors (Baden-Fuller and Winter, 2005).

Organizations who use replication strategies usually follow one of the two approaches of template or principle (Baden-Fuller and Winter, 2005). The former primarily focuses on precisely copying from the replicator to the replicatee the way how a particular routine is to be carried out, whereas the latter seeks accurate clarification for the reasons why a certain routine is successful and has a particular manner whilst allowing the replicatee considerable discretion in its enactment (Baden-Fuller and Winter, 2005).

As mentioned, routine replication processes may happen involuntarily or may be conducted intentionally. This paper focuses on deliberate routine replication activities, especially those who follow the template approach. Applying this frame of reference, 
the author will briefly present the exemplary template replication process and the role of the reverse knowledge flows.

In the case study of a leading electronics organization, D’Adderio (2014) demonstrates a quite common approach to replication. It consists of two major phases: (1) "uplifting" of a routine at its origin, and (2) its deployment at the destination.

The "uplifting" stage encompasses a careful and direct observation of the performance of routines at the origin that will be subject to replication and referencing to written manuals followed by their codification, e.g. in procedures and software (D'Adderio, 2014). In research on ambidexterity of organizations, scholars call this phase "exploration' (March, 1991).

Once formalized in detail, the routine participants at the host unit are supposed to enact the routine during the deployment phase by closely following the manuals (D’Adderio, 2014). During this phase, the replicatee's staff often receive support from the representatives of the replicator unit (instructors; Szulanski and Winter, 2002; Jonsson and Foss, 2011). This is vital because, despite the effort of knowledge formalization in the exploration phase, a substantial amount of knowledge embedded in the "transplanted" routine may still remain tacit. Scholars therefore recognize that "examples of successful routine replications typically involve the combination of codified information and instructions with extensive personal example, advice and contact" (Hodgson, 2009, p. 37). Within the template approach, it is also crucial that we avoid premature template adaptation at the host unit, as many attribute this to be the root cause of many replication failures (Szulanski and Winter, 2002; Szulanski and Jensen, 2008; Konlechner and Güttel, 2011). The deployment phase essentially aims at making the routine fully operational at the destination in order to subsequently benefit from its "exploitation".

The activities involved in the deployment phase of the routine replication processes go by forward knowledge flows (Jonsson and Foss, 2011; Friesl and Larty, 2013). Scholars emphasize here the importance of the best possible transmission of the routine-related know-how, from the source to the destination, and to the transition of acquired knowledge into knowing and operational proficiency. In the last decade, forward knowledge flows underwent many scholarly investigations and received examples of normative advice for the management practice. The same appears to apply for the (forward) replication process as such, which received recommendations on how to master the routine "transplantation" as effectively as possible (see e.g. Szulanski and Winter, 2002; McDonald, 1998). What remains underdeveloped is the understanding of the 
nature of the reverse knowledge flows and, specifically, how organizations can collect local feedback during and after replication projects and transform it into template enrichments and deployment process improvements.

\section{The Role of Reverse Knowledge Flows in Routine Replication Processes}

Alongside strong delivery focus, replication projects offer numerous learning opportunities for the replicator. If utilized correctly, these opportunities may be converted into template enrichments (Konlechner and Güttel, 2011) which, if realized, may lead to enhancements of globally utilized practices. If institutionalized, such knowledge retrieval and redeployment process benefit from the so-called economies of learning and gains agility, while the organization masters how to regularly implement the learnings on a company-wide scale. This is supposed to be particularly relevant for companies that operate in high-tech industries and dynamic markets.

Similarly to the forward knowledge flows, the reverse knowledge flows may (1) occur implicitly, (2) be intentionally designed and attended, or (3) remain ignored during routine replications. For example, Winter and Szulanski (2001, p. 735) present how subsequent replication cycles may improve the overall understanding of the so-called Arrow Core; the essential and most crucial elements of a business model or a particular routine. This can lead to Arrow Core's better codification and formalization and, thus, raises the effectiveness and efficiency (tempo and cost) of further replications by better focusing on what is truly vital within a particular routine. Unfortunately, Winter and Szulanski do not specify which mechanisms facilitate the learning about the Arrow Core. Interestingly, in the analyzed case (Banc One) the reverse knowledge flows and the corresponding learning predominantly result from failure, frustrations, and trial and error experience (Winter and Szulanski, 2001, p. 739).

D’Adderio's study from 2014 brings further interesting insights. It demonstrates the key role of socio-material mechanisms in implementing persistent reverse knowledge flows, which primarily focus on (1) the collection of local feedback about the possible adjustments and improvements and (2) their controlled orchestration with the template-in-use. This primarily emerges via a mobilization of specialists' forums - platforms for idea, experience, and knowledge sharing - and through the implementation of the Engineering Change Request tool. The use of the tool combines with a corresponding governance process led by a cross-functional governance body; the Change Review Board. Even though D’Adderio's 2014 case study does not cover a series of replication 
cycles, it supposes that the findings will be applicable in most of the long-run replication programs.

Likewise, in a study of IKEA's multinational expansion, Jonsson and Foss (2011) exemplify how local knowledge can fuel and enhance further replication cycles and create company-wide economies of learning. Noteworthy, the reverse knowledge flows at IKEA are well-organized and carefully managed. Dedicated departments implemented and coordinated knowledge management processes. Employees received clear responsibilities for the collection, examination, codification, and dissemination of potentially useful elements. The management introduced a variety of artifacts, including standard operating procedures for collection and sharing of experiential knowledge (Jonsson and Foss, 2011, p. 1091). Employees from source units often visit branches, share experiences, and instruct at host divisions. Cross-unit cooperation and joint problem solving are not uncommon. Moreover, knowledge sharing and the spirit of togetherness seem to be crucial values in IKEA's strong corporate culture. Senior management frequently refers to it, and internal magazines communicate it with the use of storytelling.

In an article on the evolution of replication strategies, Konlechner and Güttel (2011) explain how we may use local knowledge to fine-tune (or redesign) existing approaches to replication. The authors pinpoint three sources of learning: (1) invention or imitation, (2) past failures, and (3) structural drift, i.e. endogenous routine changes conceptualized by Feldmann (2000). The authors state that regular reflection, the establishment of dedicated teams for replication related matters, and centralization of training may lead to better awareness of the Arrow Core, changes in the ostensive aspects of routines, and enriched templates in the form of enhanced procedures, training agendas, and control mechanisms of procedure-practice compliance.

Building on the observations of the role of reverse knowledge flows and in the context of routine replications, it becomes clear: enhancements of subsequent replication cycles, through improvements in forward knowledge flows, require the application of learnings from previous replication attempts. Extant literature offers insight on where the local knowledge may originate and defines a few mechanisms for its conveying. Literature offers little help, however, on how to shape a structured reverse knowledge management approach, i.e. one that would combine within the same framework (1) the implementation of a routine within a new context and (2) the collection, transformation, and redeployment of local knowledge (as part of a core template). The retrofit activities (the redeployment of adjusted practices) particularly seem to require more attention as they are key for truly realizing the economies of learning. 
The approach to a routine replication program with the necessity to manage reverse knowledge flows right from the start enables the inclusion of activities related to reverse knowledge flow management into project plans - already in the preparation phase - and assign them resources like budget, time, and people, thus increasing the likelihood of their institutionalization. Otherwise, as practice shows, they may be left aside in the implementation rush, and their importance might be discovered only in case of failures or budget overruns.

\section{Structuring Reverse Knowledge Flows in a Multinational ERP Template Rollout}

\section{Research Setting}

In the attempt to identify effective reverse knowledge flow management mechanisms and elaborate a framework proposal, I draw from the longitudinal study of a successful ERP core model (template) rollout program within a leading FMCG organization, ${ }^{2}$ which has very rapidly developed over the past 20 years, largely through mergers and acquisitions of other companies from the same industry, but now experiencing a period of a more organic growth.

This setting offered a promising opportunity to explore reverse knowledge management related aspects in the context of a global replication program. Indeed, ERP adoption and system configuration significantly influence the execution of supported business processes, frequently inducing considerable changes in the performance of related routines. ${ }^{3}$ Therefore, the rollout program deals not only with pure software implementation but also - and predominantly - refers to the adjustments of operational routines, influenced through the ERP core model deployment and accomplished to reach a good software-process fit. Moreover, the rollout program tackles how local learnings were transformed into template enrichments and retrofits. Furthermore, because global ERP template rollouts frequently increase the degree of overall standardization of practices across companies - which often is their main motivation - managers should follow the decisions, solutions, and learning agreed for deployment at a particular plant in subsequent implementations. If not, then a program's budget often overruns and the total company's degree of complexity counter-productively increases along with the related costs of coordination. Therefore, this challenging context - in which the success

Respecting the request for confidentiality, we will not provide the name of the company.

3 These effects, regardless of how strong they may be, should not be confused with technological determinism, because during the actual performances of routines, supported by standard software, there is always some discretion. Furthermore, as Pentland and Feldmann (2008, p. 236) state, "research on technology and organization has largely discredited this (deterministic) perspective". 
of a program heavily depends on the proficiency in reverse knowledge flow management - allows for new insights into their effective application.

The author admits that the study was not first intended to explore reverse knowledge flows. In the beginning, the study aimed at investigating critical success factors of multinational ERP rollouts. However, as it sometimes happens in inductive studies, unexpected concepts emerged from the collected evidence ${ }^{4}$ already in the preliminary analysis of data collected in year one; in this case, they related to the management of reverse knowledge flows. Recognizing the maturity of ERP literature and the importance of reverse knowledge flows for the effectiveness of replication, the author reoriented his research and focused more on this emerging concept. The decision has only received reinforcement in the form of recurring senior management questions, such as: "What can we do to better transfer existing manufacturing practices from one plant to another by means of the standard company model that we put in place when deploying our ERP?;" "What should we do to continuously enhance the model in our ERP system with locally observed best practices, while ensuring their retrofit into the existing installed base." Thus, on the one hand, the investigation had scientific motivations while, on the other hand, represented a search for a fit-for-purpose approach to enhance the diffusion of knowledge about the best practices and their replication inside the company by means of the implemented and retrofitted ERP template.

The investigation encompasses a period of seven years (2009-2015), during which managers employed the template in twenty-five manufacturing plants and five regional offices that mainly manage finance, banking, and HR for a group of factories. Moreover, the investigation provides an in-depth, dynamic, and longitudinal overview of the replication process.

The author limited the ERP template rollout analysis to the manufacturing plants and their operations. As such, the analysis did not cover areas such as global supply chain, direct sales, Salesforce automation, financial consolidation, and group reporting, which have been supported by other applications.

\section{The Object of Analysis}

The object of this scientific inquiry is the reverse knowledge flow management approach applied in replication programs of organizational routines. As mentioned above, the

4 Such course of an inductive research endeavor is recognized as "not uncommon" in the literature on inductive research (see e.g. Czernek, 2015, p. 180-181). 
context of an ERP template rollout program offers a good setting for such an investigation. In contemporary manufacturing enterprises and especially the FMCG industry, the enactment of operational routines strongly refers to the way an ERP supports their execution. Consequently, ERP templates largely pre-define the way particular routines should be enacted. The IT industry commonly labels ERP templates as "core models," while the literature presents them as "concepts or models for the standardization of processes, functions, and data that could be implemented in a physical (ERP) system" (Huber, Alt, and Osterle, 2000, p. 4). Although, from the early Routine Theory perspective, one may treat ERP templates as artifacts or representations of the ostensive aspects of routines enclosed in a template. In practice, the influence of ERP templates goes much farther and heavily affects the way routine participants conduct tasks. Although system users can always seek workarounds, the more integrated the system and the more participants' activities happen with the use of the system, the harder to bypass the pre-agreed ways of enactment. Therefore, this paper understands the ERP template as a cluster of routines which available functionality strongly steers its enactment. Hence, most adjustments of the ERP template, if appropriately implemented, should result in changes in related routines.

As this paper gives priority to the analysis of reverse knowledge flows, the author enters not the debate on the influence of artifacts on the routine itself, as this is subject to prior scholarly investigations. This article acknowledges D’Adderio's (2011) view in this regard that artifacts reside in the "centre of routines" and interact both with their ostensive and performative aspects. Through this interaction, routine adjustments are accomplished. Thus, referring back to the definition of an ERP template, one should identify it with a cluster of routines. At first glance, this may seem a simplistic approach, but it appears sufficiently valid from the perspective of the article's purpose, collected evidence, and the observed alterations of routine performances.

The analyzed company labeled the ERP template the "standard company model." Moreover, knowing how tightly the execution of operational routines relates to integrated software, senior management strongly believed that through the cohesive deployment of a single ERP template in the manufacturing plants, they would achieve an overall unification of routines and the spread of best practices.

In the case under examination, the ERP template covered predominantly operational routines: procurement, contract management, production planning, shop floor control, inbound and outbound logistics, warehousing and inventory control, spare parts management, asset maintenance, tracking and reporting of data required by the customs authorities, finance, and controlling. 
The next part analyzes knowledge management mechanisms and their evolution in the course of the program. Noteworthy, this evolution resulted from the striving to improve the efficiency of local knowledge reuse in routine replications in order to make the replications gradually more effective.

\section{Methodology}

\section{Data Collection}

Participant Observation. The author was actively involved in the analyzed program, first as implementation consultant and, since 2011, as a manager who coordinated the work of 10-12 consultants, accountable for the quality and appropriateness of the solutions implemented in logistics and integration: inbound logistics, advanced warehousing and inventory control, outbound logistics, interfaces. During the seven years of participation in the ERP template rollout, the author was involved in related activities in 50\%-100\% of his workday; in 2009-2011 almost 100\%; in 2012-2015, 70\%-50\%. The author collected data by regularly attending numerous meetings like selected daily stand-ups, weekly project progress reviews, monthly steering group meetings, on-demand project team meetings deciding on and assessing particular solutions, system integration and acceptance testing workshops; informal discussions with other consultants, project managers, key/end users, plant managers, and other workers. The meetings amount to 700-850 in the course of the whole program. Whenever the implementation activities happened on-site, the author regularly visited the shop floor and areas with logistics and warehousing operations. Three times a week, after regular work, the author documented observations and not directly during meetings so as to not visibly decrease his perceived involvement in the gatherings. Direct observation significantly reduced the need to solely rely on interviews, which would otherwise be the main approach for gathering data otherwise. In the latter approach, the data could substantially differ from real-life experience and sheer documentation analysis, which in turn would leave room for different interpretations.

Interviews. Although participant observation was the leading data collecting approach, the author conducted more than one hundred unstructured and semi-structured interviews. Most of the informants were primarily selected from the implementation consultants involved in the project. Others were business users or practitioners involved in the enactment of various routines and partly impacted by the ERP template adoption, namely shift leaders, inventory controllers, buyers, controllers, and dispatch officers. The author carefully chose the sample of interviewees to cover most of the business areas in the ERP template: make-to-stock, distribute-to-customer, source-to-pay, record-to-report. The study interviewed informants from different levels of the 
organization both in the business and the IT function: engineers, shift leaders, business area managers, and directors.

Documentation. The study also collected relevant research data from meeting minutes, presentations, flow charts, requirement analyses, blueprint documents, steering group records, program materials, and departmental documentation. Particularly insightful data stems from the minutes of the post-project review meetings, which discussed the "lessons learned," proposed improvements, and implementation actions for subsequent replication cycles.

E-mail communication analysis. The study retrieved relevant research data from internal e-mail communication. This was particularly helpful in the first phase of the reverse knowledge flow system's maturity (see Table 1), in which local-to-global knowledge sharing was predominantly informal and unstructured, hence only capturable through direct observation or e-mails. The analysis applied to e-mail communication was a good tool for data triangulation from direct observation minutes and also helped to reduce the number of undocumented observations; remembering that these were documented in average three times per week only.

\section{Data analysis}

Data analysis agreed with the inductive approach. As the study identified different sources of local knowledge like gap log, internal kick-off records, project review minutes, and factory visit reports, diverse approaches to reverse knowledge flow management emerged, such as spontaneous alignment, functional competence owner driven, regular reviews of change requests collected in a ticketing system. The author adjusted the interview scripts and held additional interviews in order to understand them better. As such, the data analysis was iterative, included numerous returns to the field with the intention to collect more detailed information about the emerging concepts. Finally, as it became apparent that the intensity in the use of particular knowledge management carriers and approaches varied over time, the author developed the concept of the reverse knowledge flow maturity model. The model specified the different approaches to reverse knowledge management, consolidated them around the identified phases of this process like local knowledge collection, assessment and transformation, communication and reuse, and associated them with different maturity stages: spontaneous, basic governance, managed, advanced.

\section{Triangulation}

The author collected and analyzed the data from different sources for triangulation purposes. This not only allowed to cross-validate data but also see different dimensions 
of the same phenomenon. For instance, during the interviews with business key users, the author discovered that there is little evidence of local-to-global knowledge sharing practices other than those initiated and established through the center of excellence team. Moreover, in the case of knowledge securing - first step in the reverse knowledge management process - the comparison of interview data with available documentation and observation minutes revealed that, despite frequently interviewee declarations that "we regularly record knowledge about failures and resulting," no evidence of such actions could be found in the initial phase of the program.

\section{Findings}

The case study demonstrates that during the seven years and in the course of multiple implementations, the ERP template was subject to several adjustments in order to fit new requirements, eliminate observed shortcomings, and adopt learnings and ideas from the deployment sites. This underlines the importance of deliberate management of reverse knowledge flows and shows how it matured throughout the program.

In 2009, the ERP landscape of the company consisted of numerous standalone ERP systems that supported the activities of individual manufacturing plants (or groups of plants) in particular regions. On the one hand, this state effected from the way the company has grown over the last twenty years through mergers and acquisitions while, on the other hand, resulted from its inertia and strict focus on business priorities with less attention to the consistency of the information systems landscape.

The objectives of the ERP template deployment program mainly related to the reduction of (1) the total cost of ownership of the ERP platform through simplification and (2) the standardization of manufacturing processes along with the corresponding information flows, that allowed for more consistent group reporting and integration with global functions, such as product development, global planning, global procurement, and global supply chain. After a series of mergers and acquisitions, the ERP implementation program could be considered one of the first attempts to increase the degree of intra-company integration. The standardization of operations through ERP template implementation is not uncommon across various industries and is considered key for the company's operational efficiency. Noteworthy, the main competitors have launched analogous programs, however varying in the rigidness of the template and the level of its enforcement. 
The program and project organization was quite common for IT projects. The program organized the ERP implementation teams "per factory" which included an IS project manager and a group of functional consultants; both internal employees and external contractors. The program organized corresponding teams on the plant side as well. These project teams consisted of a project sponsor that usually was the factory manager, a business project manager that could be the local IT manager, production manager, or factory controller, and key users from the functional areas in scope. Both the IS project manager and business project manager regularly reported on the progress, budget utilization, timelines, risks, and impediments to the project steering group which formed the primary governance mechanism for the particular project. If the project encountered unsolvable issues on its level, the managers escalated them to a higher-level steering group with senior leadership team members like the director of operations or the director of supply chain services.

Most of the IS staff involved in the ERP rollout regularly worked within a central department called the center of excellence - specialized in supporting the manufacturing operations with different information solutions through project and service delivery - aiming at ensuring business continuity and the desired level of process efficiency. Noteworthy, the sales and global supply chain operations received the support of similar centers of excellence.

The project delivery approach consisted of five major phases: (1) inception, (2) definition, (3) regular implementation, (4) go-live activities, and (5) post go-live support and handover to service delivery.

During the inception phase, the project held initial meetings with the factory representatives and conducted scoping activities.

The definition phase elaborated the site-specific blueprint, addressed the identified processes, detailed the functional configuration and the to-be ways of working and routines, finally pointed at gaps between the template and the requirements. The project sponsor and client signed off the blueprint, which constituted the basis for subsequent implementation activities as such. At this stage, the teams discussed the first differences between the template and as-is routines. They created a "gap log" document that listed the major differences. If no agreement on the local project level appeared on how to address them, which was usually the case, the project steering group received an escalation for the decision on how to proceed with the gaps. Then, the steering group discussed the extent of local adaptation. The IS representatives strongly advised a straightforward template deployment while the factory teams, on the other hand, 
usually resisted the plan and protected their local and home-grown routines. In the case of lasting disagreement, they escalated the conflict to the higher-level steering group. Often, this level proposed no clear decisions but only vague hints on how to proceed. This incited another round of local project level discussions, according to the new directions, and informed new proposals for the blueprint. If disagreement persisted, the escalation process iterated, which negatively impacted the project timelines and budget.

In parallel to the steering group escalation cycles, on the project level, informal negotiations continued to elaborate an acceptable compromise. They often ended in an agreement to keep selected routines unchanged, especially the ones marked as crucial for factory performance, and adjust the software. For the remaining routines, the teams implemented the template without any amendments. The confrontation of the local and central views at the design stage was the first place which identified local knowledge, recorded it, discussed, and potentially transformed into template adaptations, that is, software customizations.

The next stage consisted of typical implementation activities, namely implementation workshops, software configuration, user training, integration testing, user acceptance tests, and go-live preparation. When the previous stage identified the gaps between the template and as-is routines well, this stage usually proceeded smoothly. If not, there happened similar struggles as in the definition phase. Moreover, in this project phase, both the key and end users experienced the system for the first time. It frequently led to frictions, as they confronted old habits with a new reality; among others, different user interface, transaction menu structure, searching mechanisms, and document formats. The teams could usually manage most of the conflicts on the project level.

Once the user acceptance test received sign-off, the go-live began and conducted activities like data migration, final software configuration, opening balances comparison, and clarification of encountered differences.

After activating the new system, the teams typically conducted a 4-6 weeks post go-live aftercare, during which the implementation consultants actively helped the users on-site in the execution of transactions, corrections and rollbacks of mistakes, delivering on-demand short trainings and answering additional inquiries. During this stage, the consultants conducted handover to the service delivery team by explaining the particularities of the implementation to the support desk staff and providing them with project documentation like the scoping document, the blueprint, and user manuals. 
The rollout program started in 2009 with the aim to implement the ERP template in the same year in one factory in Poland, one in France, and two in Germany. The program began after a decision on group level to make a specific ERP solution standard for most of the tier 1 manufacturing sites. A recent release of a new version of the ERP suite by the vendor also significantly influenced this decision, since the new version significantly enhanced its features and user interface. Moreover, the new ERP suite was considered a good fit for manufacturing operations and had a lower total cost of ownership than other ERP systems in the group.

In 2009, the template was not well-documented. Most referred to the template as a model implemented in a few factories with an old ERP system. The particularities of the old model only appeared in the incomplete documentation.

Nevertheless, the 2009 projects in Poland, France, and Germany started with the above delivery approach. The teams detailed one of the first representations of the template in the blueprints of the individual implementations. These agreed with each other, as there was a limited number of consultants who conducted the projects, knew each other well, and proactively aligned the topics that required collective attention. The alignment was largely informal and spontaneous. Once the projects finished, they documented the template in the form of a collection of interrelated process flows modeled in the ERP system and agreed to copy them as such to any new instance of the software and any other factory.

In the Polish factory, the implementation went rather smoothly and finished in early 2010. In the case of the German factories, several gaps appeared. The major gaps related to procurement, shop floor data collection, and outbound logistics routines. The teams addressed these by software customizations that kept the as-is routines. However, the decision to not adapt to the template led to the postponement of the project by almost one year and budget overruns.

In 2010, the implementations of the one French and two German factories finished. The firm also decided to replicate the template in two additional French factories. These deployment projects documented the template in a document called the "standard company model." The document included the adjustments for the two German factories and the first French one into the model. During the 2010 implementation in the second and third French factory, the teams introduced the template with few changes, the main one relating to the deployment of an advanced planning and scheduling module and standardization of the related scheduling routines; which was considered as template extension. 
In 2011, the rollout program truly accelerated. The plan to implement the ERP template at five factories - two in Russia, one in Ukraine, and two in Morocco - within a year increased the complexity of the program and the number of interdependencies between the project teams. The firm hired additional consultants and project managers and assigned them to different implementation teams. Most of them had rich application knowledge but no previous experience with the company. They received a series of trainings aiming to familiarize them with the template and the available functional solutions.

Simultaneously, representatives from the factories with the new template often "supplied" the implementation consultants with new requirements or directly submitted change requests and new demands through a support desk system. After gaining some experience, the key users at the factories simply spotted various opportunities on how to increase the efficiency of various processes by means of software reconfiguration, additional customizations or changes in the organizational routines. Furthermore, changes within the business called for additional functionality or a reconfiguration of the existing one; these changes were new legal regulations, fluctuations in finished product sales, or introduction of new shipping patterns.

The management of the center of excellence realized then that the establishment of structured governance processes around change management would be fundamental to maintain the consistency of the template. On the other hand, the structured governance processes would allow factories to benefit from the recent template enhancements, which originated both from new projects demands and requirements from the available installed base. Thus, the management acted in numerous areas.

First, they identified and attended the potential sources of new demand: gap logs from new projects and change requests from the installed base. Secondly, they decided to record every request for a change in a dedicated application in order to capture scriptural and verbal demands. Simultaneously, they established the "functional competence owner" role in particular functional domains: procurement, logistics, planning, customs, manufacturing execution, integration, finance, and controlling. The competence owners supervised the acceptance of change requests, guarded the quality of solutions, and decide which of them to admit and embed in the template in order to reuse them in other factories. The competence owners also reviewed blueprints for implementation projects to ensure the replication of good practices into plants, in which the ERP core model was to appear. In case of conflicts between the project teams - especially the IS and the factory team - the competence owners traveled to the project locations to persuade the local teams to why it is worth to accept a particular practice 
or piece of functionality. Frequently, one of the key convincing arguments was the efficient functioning of a given template routine in a different factory. The competence owner roles went to the most experienced internal consultants who knew the application software and the business processes very well, had a recognizable implementation track record, strong exposure, and influencing skills. They played a pivotal role in the governance of reverse knowledge flows, and their orchestration with the forward knowledge flows in rollout projects. They simultaneously acted as functional architects and idea brokers, thus positioned on top of the collection of local knowledge, its assessment and transformation into working functionality, communication to other factories, and reuse or retrofit decisions. The main criteria for assessment were the reuse potential or criticality of the requirement and its impact on business performance.

During 2011 and in the course of the template rollout in Russian, Ukrainian, and Moroccan factories, the structured governance of the reverse knowledge flows became a well-respected and regularly used practice, both at the center of excellence and by the local key users.

In 2012, the rollout plan involved the deployment of the template in six factories: two in Spain, one in Macedonia, on in the Netherlands, one in Ireland, and one in the USA. At this time, already eleven factories were using the template and the enhanced version of the ERP system. The governance of the reverse knowledge flows and their orchestration with the template and running replications settled well. The collection of new local demands continued and retained support via the ticketing system. The competence owners still played a crucial role but gradually became overloaded. The management responded to this challenge by creating an additional hierarchical layer: solution managers. Many competence owners received promotions to the roles of solution managers, while high-potential consultants - the roles of competence owners. While the competence owners continued to assess the demands collected from both projects and the installed base and kept the lead on solution alignment in the design phase of new replications, the solution managers assumed many of stakeholder management activities. They conducted regular visits to plants with the new ERP template in order to identify unregistered requirements, areas for improvement, and unnoticed noteworthy practices. Simultaneously, the solution managers sought more alignment with the representatives of the company's central functions in order to establish global approaches to different local routines apt for company-wide implementation. After every local visit, the center of excellence management team received a presentation and a visit report. Based on the findings, the center assigned actions mostly applied by the competence owners. 
In order to more quickly orchestrate new project demands with the template, the firm introduced a useful routine of "internal kick-off." Just after gap analysis, the project manager gave a short presentation to all solution managers and competence owners about the main characteristics of the implementation context and the main gaps identified. This facilitated the alignment of different functional domains and allowed for quick decisions, suggesting the reuse of various practices recently applied to the template and very early in the project's lifecycle.

Another beneficial practice began in 2013 - project review session - which aimed at reviewing the key aspects of a project and recording lessons learned from the business. During this session, the project manager presented their point of view on several aspects of the project; its scope, deliverables, risks, costs, benefits, and communication. In the end, the project manager marked the elements that need improvement in subsequent rollouts. What followed was an open discussion on any identifiable techniques or innovations that could be used in subsequent replications. The teams recorded the outcomes in a document stored in the company's intranet. Noteworthy, this practice was a part of the project methodology (PMP) used in the organization but previously largely ignored.

In 2013-2015, the firm deployed the ERP template in further seven factories: in Spain, Sweden, Turkey, Belgium, Puerto Rico, Corsica, and Taiwan. During this period, the firm introduced additional mechanisms for reverse knowledge management. One of the most significant was the launch of "user groups." User groups were functionally-oriented communities that regularly met to discuss whether given practices should become standard in the company or whether particular requirements should enter the template. Thus, the decision responsibility was moved from competence owners to the user community. The groups consisted of representatives of leading factories from different regions and corresponding competence owners from the center of excellence.

At the same time, to better distribute the knowledge about different routines, the center of excellence started to regularly issue a release bulletin informing about the recent template extensions. This practice found much appreciation at the local level.

In summary, throughout the seven years, the firm introduced a set of practices, roles, responsibilities, and supporting tooling to deliberately and efficiently manage the reverse knowledge flows. The company recognized that without collecting, assessing, transforming, and reusing the local learnings in a structured, disciplined, and regular manner, its manufacturing operations would suffer from excessive complexity and lose the chance to exploit the economies of learning. Such view acknowledges the (initial) diversity of performances of similar routines in different factories and the need to 
standardize them through the deployment of the core ERP model. The diversity effected from the way the company grew in the past; that is, through acquiring competitor organizations and making them part of the same group. Simultaneously, the firm perceived this diversity as the potential source of learning opportunities about local best practices which could be elevated to the corporate level and become company standards.

At the same time, one should mention that the approach to reverse knowledge flow management matured over time, alongside the number of updated manufacturing sites, the increasing pace of the replication program, and the number of different local requirements.

In the early days of the ERP template rollout, the approach was largely informal and based on the spontaneous interaction of consultants. In the course of the program, the rollout gained more structure. A system for change requests and new demand recording appeared, along with basic procedures for capturing local knowledge and the roles of competence owners, who received the responsibility to assess, transform, and reuse solutions. These actions enabled the basic governance of reverse knowledge flows. Forced by the increasing pace of the program and the overload of competence owners, the company moved some responsibilities to solution managers and institutionalized internal kick-off and project review meetings. In the final maturity phase, the firm formed functional communities (user groups) to evaluate the suitability of selected practices to enter the overall standard. The content of the template has started to be regularly communicated in release bulletins to ensure sufficient local awareness.

\section{Conclusions}

The evolution of the maturity of reverse knowledge flow management presents Table 1. Table 1 shows that along with the increasing number of parallel replications in the scope of the program and replications, local knowledge derives from (1) an increasing number of sources and (2) an increasing variety of approaches like direct communication, technology, review meetings, or the establishment of dedicated communities. Furthermore, with the growing maturity, (3) participants assess and transform local knowledge in a progressively structured way and (4) more intensively communicated to the broader organization via dedicated organizational roles, communities, and meetings. Finally, (6) the reuse of knowledge that is locally acquired and centrally assessed and transformed is initially incidental, but later assumes a place in subsequent replication cycles and regular software upgrade projects so that, in the final maturity phase, it receives a central drive, funding, and initiative. 


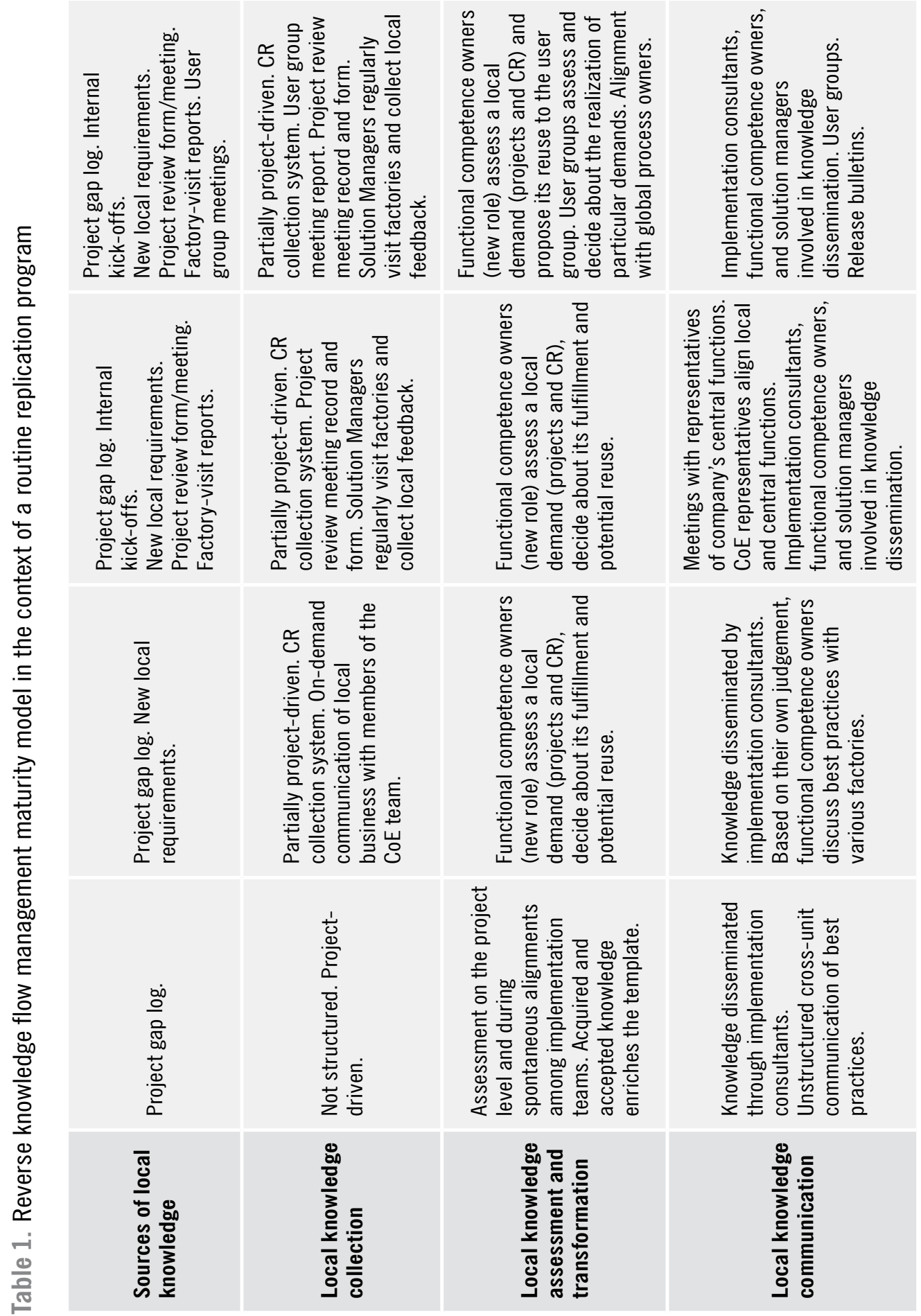



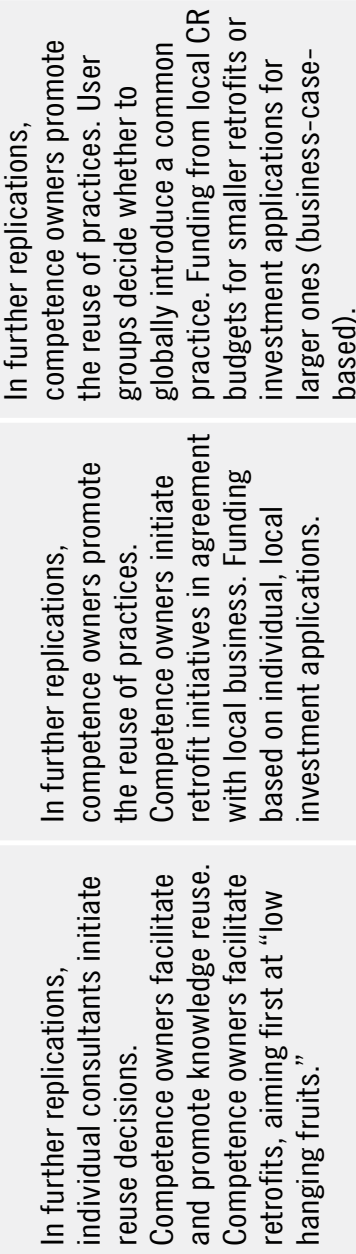

용



$\vec{x} \quad \vec{x}$

폼

总

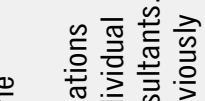

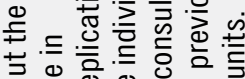

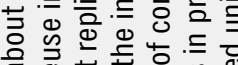
ชิ

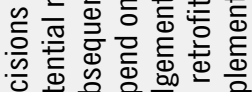

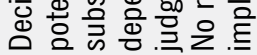
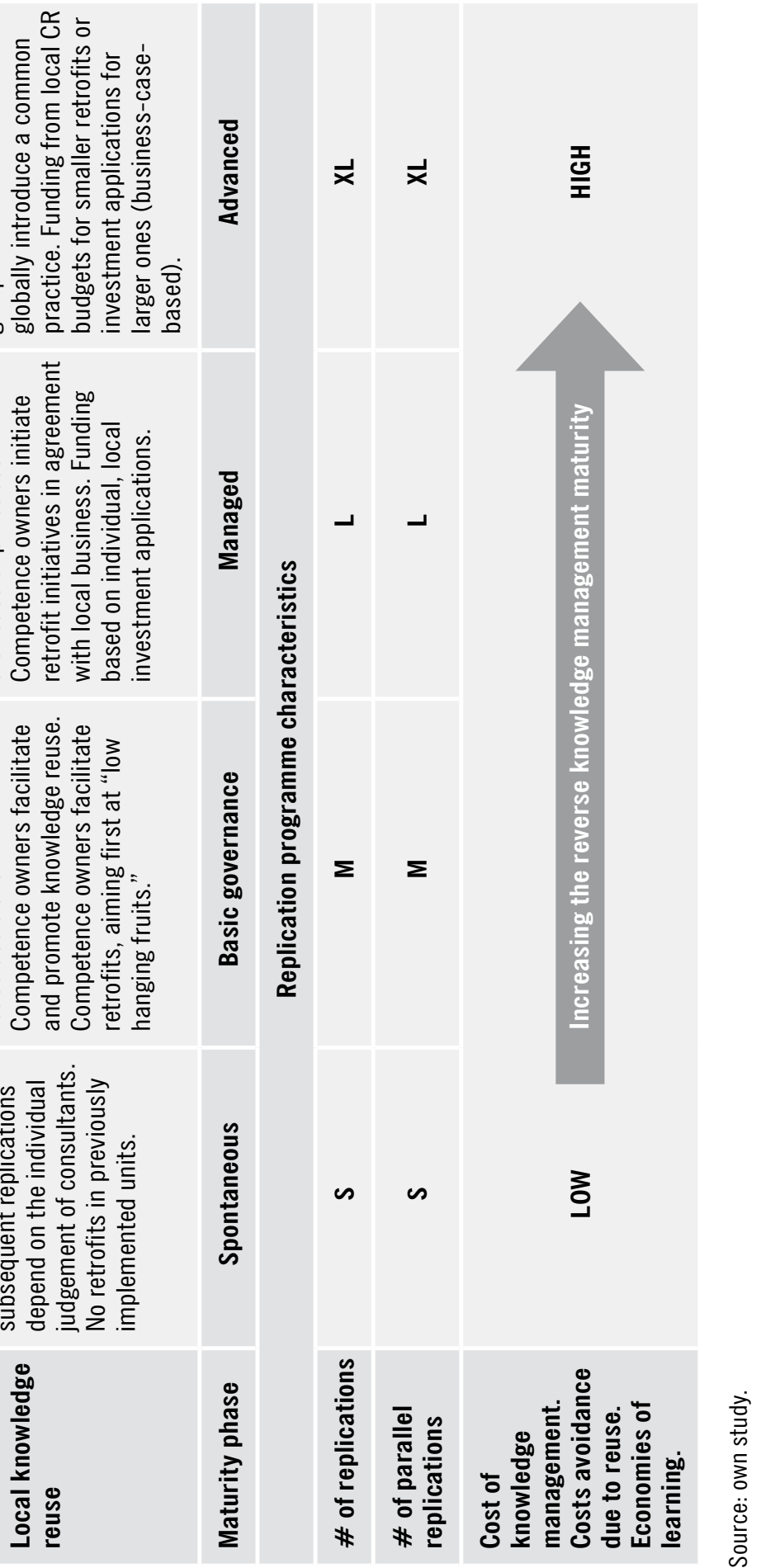

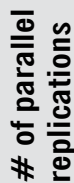


One can generally characterize the maturing reverse knowledge flow management by the increasing number of potential knowledge sources and knowledge retrieval mechanisms in use. Moreover, by the increasing perception of the significance of local knowledge and the value of its possible reuse within the broader organization. Thus, local knowledge assessment, transformation, and reuse decisions become more centralized. However, one should apply precautions to avoid the "headquarters knows best syndrome" (Bouquet, Birkinshaw, and Barsoux, 2016). At the same time, one must admit that with the maturing of reverse knowledge flow management rises the cost of knowledge management. Nevertheless, we should expect that the economies of learning will offset this cost, leading in turn to cost avoidance in other areas, through efficiency gains, proportional to the number of adjusted routines in result of the global deployment of locally acquired knowledge.

The case study findings offer useful advice to scholars and practitioners by:

- demonstrating how local knowledge may be identified, collected, transformed, analyzed, and applied in the wider organization through template enrichments and selective retrofits;

- showing that - to benefit from local learnings on a company-wide scale - the reverse knowledge flows must receive deliberate management and base on well-established processes with assigned resources, clear responsibilities for various steps of the knowledge flow process - from identification up to retrofit related deployments - and various socio-material mechanisms like ticketing systems, knowledge bases, user groups, and project review documents.

- evidencing that - to effectively support routine replication programs - the reverse knowledge flow management activities must constitute a consistent system and align with the routine deployment stages of the replication program (see the proposal in Figure 1);

- creating the awareness that deliberate and disciplined reverse knowledge flow management must already emerge from the planning phase of the replication program. It also needs to become truly embedded into the program in order to institutionalize local feedback sharing and collection in every replication right from the start, thus making it an obvious and common practice. The firm must put tools in place to store local knowledge which has been captured and codified. The management must instruct project team members to regularly keep a record of the routines which differ from the template, project review insights, and of any other local feedback, which may potentially result in template enhancements. Simultaneously, as particular replication projects finish and the transplanted routines become operational, further mechanisms must 
appear to facilitate structured feedback collection, its central assessment, transformation, and retrofit investment planning;

- providing a working example of the possible design of a reverse knowledge management system which facilitates routine replication.

Figure 1. A structured approach to reverse knowledge flow management within a routine replication program

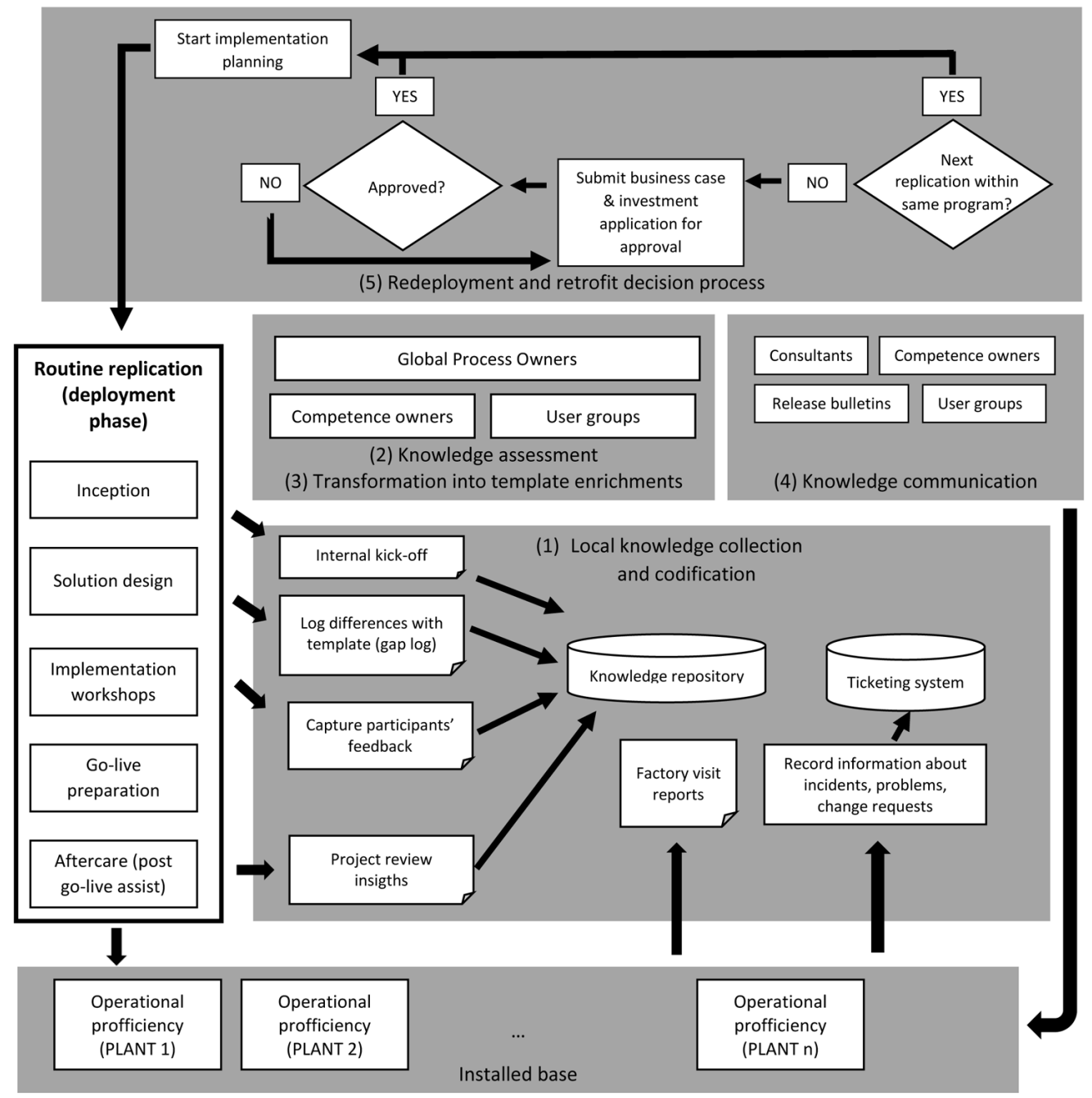

Source: own study.

In a well-functioning reverse knowledge management system, the retrieved knowledge must undergo regular review and assessment. One must not accept all ideas, but none 
should be ignored; each requires a brief review and feedback to the originator. The knowledge assessment process should be rather centralized in order to keep consistency within the set of routines in global use at different sites. The more mature the reverse knowledge flow management system is, the more this responsibility should shift towards central business functions.

One should transform the most promising ideas into template enrichments and (1) deploy them either in the subsequent replication cycles or (2) retrofit in the current base. As the latter option may result in significant transformation costs, the decision should emerge from a formal investment approval process. Depending on the current maturity of the reverse knowledge flow management system, the investment applications may be raised by the replication program team members (low maturity), the competence owners or center of excellence management team (medium maturity), central business governance bodies or cross-functional roles (high maturity). Although sometimes costly, regular retrofits are unavoidable and necessary to maintain the overall consistency of the routine variants in use across the local sites. In every business, there are numerous opportunities for smart adjustments of organizational routines without the necessity to mobilize a dedicated program. For instance, with regard to routines heavily supported by IT systems, obligatory software upgrade projects are frequently considered as a good opportunity for routine adjustments, like increasing the degree of automation within the shop floor replenishment routine.

The key element of such system is the regular communication about the routines to the wider organization and local units. This is fundamental because the template receives regular updates and the most recent versions of the routines appear merely within the latest replications. Without systematic communication towards local units, the sites after past replications would not know about recent improvements at other sites and, thus, the economies of learning could not materialize on a wider scale. The information about enhanced routines can be conveyed to the local units by release bulletins, consultants, competence owners, and managers from central business units who regularly visit local sites and various communities. The more mature the reverse knowledge flow management system is, the more frequent the communication and the greater the variety of methods of knowledge dissemination.

The presented maturity model along with the proposed approach to the management of reverse knowledge flows in routine replication programs adds to the literature on organizational routines by offering a hint on how subsequent replications can improve through the deployment of an enriched template, which stems from a structured 
reverse knowledge flow management system. At the same time, they provide practitioners with solutions proven and successful in a global organization.

In general, the findings presented in this article contribute to the research stream, which investigates how subsequent replication cycles could be enhanced by applying the learnings from previous iterations. Specifically, how and by means of which mechanisms can those learnings be retrieved, assessed, and transformed into adjustments and enrichments of the replicated template. Combining structured ways of using local knowledge and its effective transformation into template enhancements with the available template deployment methods could facilitate the development of more comprehensive replication approaches like combining exploration and exploitation within the same program methodology.

\section{Limitations and Directions for Further Research}

The presented frameworks originate from an IT-driven routine replication program and observations made in FMCG industry. As such, their general usefulness and generalizability to other organizational settings and replication programs of different character may be limited. ${ }^{5}$ The presented models should be therefore subject to further scientific inquiry and target other industries and settings, in which their management is not so much IT-driven as in the presented case.

Other research directions concerning reverse knowledge flows in the routine replication context should be of major interest for the management science and practice. One could think for instance about (1) the operationalization of the economies of learning, (2) the factors which most contribute to their emergence, and (3) the impact of reverse knowledge management system's maturity on the efficiency and effectiveness of a routine's replication. Besides theory building, the author supposes that unraveling these research problems could deliver useful insight for business practitioners involved in the preparation of business cases and investment applications, which are intended to justify investments in reverse knowledge management systems meant to enhance the replication of best practice routines inside an organization.

\footnotetext{
5 Nevertheless, the author supposes that the presented frameworks may have significant transfer potential to non-IT-related replication programs because the underlying key principles seem to have a general applicability potential. The key principles are to start the replication project aware that it will deliver a lot of local knowledge, which is worth capturing; retrieve local knowledge from a variety of sources and in many different ways; assess and transform local knowledge centrally; then retrofit it globally and, first, where it costs less. Moreover, the presented frameworks have been already successfully tested in a company from the Food and Beverage industry - in the replication of quality control routines - after some representatives of the company received information from the author of this paper about his findings.
} 


\section{References}

Aime, S.J., Johnson, S., Ridge, J.W. and Hill, A.D. (2010). The routine may be stable but the advantage is not: Competitive implications of key employee mobility. Strategic Management Journal, 31(1): 75-87, http://dx.doi.org/10.1002/smj.809

Argote, L. and Ingram, P. (2000). Knowledge transfer: a basis for competitive advantage in firms. Organizational Behavior and Human Decision Processes, 82: 150-169, http://dx.doi.org/10.1006/obhd.2000.2893

Baden-Fuller, C. and Winter, S.G. (2005). Replicating organizational knowledge. Working Paper 0515, Papers on Economics and Evolution, Max-Planck-Institute of Economics: 1-40.

Becker, M. and Lazaric, N. (2003). The influence of knowledge in the replication of routines. Économie appliquée: archives de l'Institut de science économique appliquée, 56(3): 65-94.

Bertels, S., Howard-Grenville, J. and Pek, S. (2016). Cultural molding, shielding, and shoring at Oilco: The role of culture in the integration of routines. Organization Science, 27(3): 573-593, http://dx.doi.org/10.1287/orsc.2016.1052.

Bouquet, C., Birkinshaw, J. and Barsoux, J.-L. (2016). Fighting the "Headquarters Knows Best" Syndrome. MIT Sloan Management Review, 57(2): 59-66.

Czernek, K. (2015). Wprowadzenie do badań jakościowych w naukach o zarządzaniu. In: W. Czakon (ed.), Podstawy metodologii badań w naukach o zarzq̨dzaniu. Warszawa: Wolters Kluwer Polska.

D’Adderio, L. (2011). Artifacts at the centre of routines. Performing the material turn in routines theory. Journal of Institutional Economics, 7: 187-230.

D’Adderio, L. (2014). The replication dilemma unraveled: How organizations enact multiple goals in routine transfer. Organization Science, 25(5): 1325-1350, http://dx.doi.org/10.1287/orsc.2014.0913

Feldman, M.S. (2000). Organizational routines as a source of continuous change. Organization science, 11(6): 611-629, http://dx.doi.org/10.1287/orsc.11.6.611.12529

Friesl, M. and Larty, J. (2013). Replication of routines in organizations: existing literature and new perspectives. International Journal of Management Reviews, 15(1): 106-122, http://dx.doi.org/10.1111/j.1468-2370.2012.00340.x

Gupta, A., Hoopes, D.G. and Knott, A.M. (2015). Redesigning routines for replication. Strategic Management Journal, 36(6): 851-871, http://dx.doi.org/10.1002/smj.2254

Hodgson, G.M. (2009), The Nature and Replication of Routines. In: M. Becker and N. Lazaric (eds.), Organizational Routines: Advancing Empirical Research. Cheltencham UK, Northampton, NA USA: Edward Elgar, http://dx.doi.org/10.4337/9781848447240.00008

Huber, T., Alt, R. and Osterle, H. (2000). Templates-instruments for standardizing ERP systems. In: System Sciences, 2000. Proceedings of the 33rd Annual Hawaii International Conference on Science Systems HICSS, Maui, Hawaii, http://dx.doi.org/10.1109/HICSS.2000.926906

Jonsson, A. and Foss, N.J. (2011). International expansion through flexible replication: learning from the international experience of IKEA. Journal of International Business Studies, 42: 1079-1102, http://dx.doi.org/10.1057/jibs.2011.32

Konlechner, S. (2011). Spiel's noch einmal, Sam. Austrian Management Review, 1: 34-44.

Konlechner, S. and Güttel, W.H. (2011). Die Evolution von Replikationsstrategien im Spannungfeld von Exploration und Exploitation. In: M. Stephan and M. Kerber (eds.), Jahrbuch strategisches Kompetenzmanagement: "Ambidextrie": Der unternehmerische Drahtseilakt zwischen Ressourcenexploration und exploitation, 4: 27-56. 
Madhok, A. (1997). Cost, value and foreign market entry mode: The transaction and the firm. Strategic Management Journal, 18(1): 39-61, http://dx.doi.org/10.1002/(SICI)1097-0266(199701)18:1\%3C39::AID-SMJ841\%3E3.3.CO;2-A

March, J.G. (1991). Exploration and exploitation in organizational learning. Organization Science, 2: 71-87, http://dx.doi.org/10.1287/orsc.2.1.71

McDonald, C. (1998). The evolution of Intel's copy exactly policy. Intel Technology Journal, Q4: 1-6.

Maritan, C.A. and Brush, T.H. (2003). Heterogeneity and transferring practices: implementing flow manufacturing in multiple plants. Strategic Management Journal, 24: 945-959, http://dx.doi.org/10.1002/smj.311

Nelson, R.R. and Winter, S.G. (1982). An Evolutionary Theory of Economic Change. Cambridge.

Orlikowski, W.J. (2002). Knowing in practice: Enacting a collective capability in distributed organizing. Organization Science, 13(3): 249-273, http://dx.doi.org/10.1287/orsc.13.3.249.2776

Patora-Wysocka, Z. (2015). Spontaneous action and everyday practice in the fashion business. Fibres \& Textiles in Eastern Europe, 4(112): 8-13, http://dx.doi.org/10.5604/12303666.1152700

Pisano, G.P. (1994). Knowledge, integration, and the locus of learning: An empirical analysis of process development. Strategic Management Journal, 15(S1): 85-100, http://dx.doi.org/10.1002/smj.4250150907

Pentland, B.T. and Feldman, M.S. (2008. Designing routines: On the folly of designing artifacts, while hoping for patterns of action. Information \& Organization, 18: 235-250, http://dx.doi.org/10.1016/j.infoandorg.2008.08.001

Rivkin, J.W. (2001). Reproducing knowledge: replication without imitation at moderate complexity. Organization Science, 12: 274-293, http://dx.doi.org/10.1287/orsc.12.3.274.10106

Szulanski, G. (1996). Exploring internal stickiness: impediments to the transfer of best practice within the firm. Strategic Management Journal, 17: 27-43, http://dx.doi.org/10.1002/smj.4250171105

Szulanski, G., Cappetta, R. and Jensen, R.J. (2004), When and How Trustworthiness Matters: Knowledge Transfer and the Moderating Effect of Causal Ambiguity. Organization Science, 15(5): 600-613, http://dx.doi.org/10.1287/orsc.1040.0096

Szulanski, G. and Jensen, R.J. (2004). Overcoming stickiness: An empirical investigation of the role of the template in the replication of organizational routines. Managerial and Decision Economics, 25(6-7): 347-363, http://dx.doi.org/10.1002/mde.1195

Szulanski, G. and Jensen, R.J. (2008). Growing through copying: the negative consequences of innovation on franchise network growth. Research Policy, 37: 1732-1741, http://dx.doi.org/10.1016/j.respol.2008.08.012

Szulanski, G. and Winter, S. (2002). Getting it right the second time. Harvard Business Review: 62-69.

Winter, S.G. and Szulanski, G. (2001). Replication as strategy. Organization Science, 12(6): 730-743, http://dx.doi.org/10.1287/orsc.12.6.730.10084

Winter, S.G. and Szulanski, G. (2002). Replication of Organizational Routines: Conceptualizing the Exploitation of Knowledge Assets. In: C.W. Choo and N. Bontis (eds.), The strategic management of intellectual capital and organizational knowledge. Oxford: Oxford University Press.

Winter, S.G., Szulanski, G., Ringov, D., Jensen, R.J. (2012). Reproducing Knowledge: Inaccurate Replication and Failure in Franchise Organizations. Organization Science, 23(5): 672-685, http://dx.doi.org/10.1287/orsc.1110.0663

Zander, U. and Kogut, B. (1995), Knowledge and the speed of the transfer and imitation of organizational capabilities: An empirical test. Organization Science, 6(1): 76-92,

http://dx.doi.org/10.1287/orsc.6.1.76 
Zollo, M. and Winter, S.G. (2002). Deliberate learning and the evolution of dynamic Capabilities, Organization Science, 13: 339-352, http://dx.doi.org/10.1287/orsc.13.3.339.2780

Yan-Liang, C. and Chuang, G. (2014), Study on Replication of Routines in Organizations Based on Organization Ambidexterity Competence. In 2014 International Conference on Economic Management and Trade Cooperation (EMTC 2014). Atlantis Press,

http://dx.doi.org/10.2991/emtc-14.2014.34 